\title{
Tip Conductor Coil Device
}

National Cancer Institute

\section{Source}

National Cancer Institute. Tip Conductor Coil Device. NCI Thesaurus. Code C49879.

A coil associated with a tip conductor voltage tester. 